Article

\title{
The Impacts of Water Demand and Its Implications for Future Surface Water Resource Management: The Case of Tanzania's Wami Ruvu Basin (WRB)
}

\author{
Mngereza Miraji ${ }^{1, * D}$, Jie Liu ${ }^{1}$ and Chunmiao Zheng ${ }^{1,2}$ \\ 1 Institute of Water Sciences, College of Engineering, Peking University, Beijing 100871, China; \\ jie.liu@pku.edu.cn (J.L.); zhengcm@sustc.edu.cn (C.Z.) \\ 2 School of Environmental Science and Engineering, Southern University of Science and Technology, \\ Shenzhen 518055, China \\ * Correspondence: mngereza@gmail.com
}

Received: 11 May 2019; Accepted: 14 June 2019; Published: 19 June 2019

\begin{abstract}
River basins around the world face similar issues of water scarcity, deficient infrastructure, and great disparities in water availability between sub-regions, both within and between countries. In this study, different strategies under the Water Evaluation and Planning system (WEAP) were assessed to mitigate water overuse practices under the Current Trend (CT), Economic Growth (EG), and Demand Side Management (DSM) scenarios in relation to current and future statuses of Tanzania's Wami Ruvu Basin (WRB). The results show that neither domestic nor irrigation water demand will be met based on the current trend. Under the CT scenario, the total water demand is projected to rise from 1050.0 million cubic meters in the year 2015, to 2122.9 million cubic meters by the year 2035, while under the DSM scenario the demand dropped to 990.0 million cubic meters in the year 2015 and to 1715.8 million cubic meters by the year 2035. This study reveals that there is a positive correlation between the highest surface runoff events and the highest unmet demand events in the basin. Terrestrial water demand alters the hydrological cycle of a catchment by modifying parameters such as surface runoff, particularly in small catchments. The results of this study prove that DSM strategies are more amenable to mitigate the impacts and implications of water demand, as they increase water sustainability and ensure ecosystem security by reducing the annual water demands and surface runoff by $15 \%$ and $2 \%$, respectively.
\end{abstract}

Keywords: Water Evaluation and Planning system (WEAP); surface water; basin water allocation; Wami Ruvu; Tanzania; Africa

\section{Introduction}

Over the period between 1962 and 2011, the global per capita freshwater stock declined by 54\%, with decreases of 75\% occurring in Sub-Saharan Africa (SSA), 71\% in the Middle East and North Africa (MENA), 64\% in South Asia, 61\% in Latin America and the Caribbean, 52\% in East Asia and the Pacific, and $41 \%$ in North America [1]. It has been noted that components of the terrestrial water cycle (groundwater, soil moisture, surface waters, snow, and ice) appear to be trending below previous ranges due to climate change, anthropogenic activities, and excessive water abstraction [2]. This is leading to large challenges in managing water demand in rapidly developing regions such as Africa, due to high spatial and temporal variability in the availability of water resources and limited amounts of total water availability across expansive semi-arid portions of the continent [3].

Global water extraction is projected to increase by $50 \%$ by 2100 , and, under a "business as usual" scenario, about half of the world's population is projected to reside in water basins by 2050, where more than $40 \%$ of the world's available water is extracted [4]. Africa's population is projected to continue to 
increase by an average of $2 \%$ per year, and $22 \%$ of the world's population is expected to live in Africa by 2050. Consequently, more water will be withdrawn, more energy will be used, and more water will be required to produce the necessary amount of food and energy [5]. Recent studies have shown that climate change, extensive economic development, population growth, water pollution, and extensive water abstraction are the main challenges that have altered the natural hydrologic regime in most of Africa's river basins, including the Sokoto Rima River basin [6], the Didessa Sub-basin [7], the Ouémé River basin [8], the Drâa basin [9], and the Mara River Basin [10].

In order to manage such vulnerable hydrological systems, as well as social influences and their management concepts, effective Integrated Water Resource Management (IWRM) models are needed [11]. For example, the Water Evaluation and Planning system (WEAP) model has been widely used to improve uncoordinated water resources in the Olifants River [12] and the Ouémé River [8], to improve water resource allocation in the Ewaso River [13], and the Didessa River [7], to improve water availability and future demands in the Sokoto Rima River basin [6] and the Niger River [14], to examine the impact of climate change on water availability in the Drâa basin [9], and to improve water resource planning. The WEAP model is considered to be the most suitable available method for IWRM at the basin level, due to its robust decision-making support, scenario generation features, low data intensity, and ability to handle the aggregated to disaggregated water management demands of various sectors $[15,16]$.

Contrary to previous studies [6-9,12-14], this study simulates the impacts of surface water demand and its implications for rapidly developing regions such as SSA by applying the WEAP model based on future water demand scenarios in Tanzania's Wami Ruvu Basin (WRB). Three of the basin's cities—Dar es Salaam, Morogoro, and Dodoma—are recognized as Tanzania's economic, agricultural, and political centers, respectively. About $80 \%$ of the inhabitants of the WRB live in urban areas, while $20 \%$ live in rural areas, thus, the population is very urbanized compared to the rest of the country, where $20 \%$ live in urban areas and $80 \%$ live in rural areas [17].

\section{Materials and Methods}

\subsection{Description of the Study Area}

The WRB is located in Eastern Tanzania. The basin covers a total area of $72,930 \mathrm{~km}^{2}$, and lies between longitudes $35^{\circ} 30^{\prime} 00^{\prime \prime}$ and $40^{\circ} 00^{\prime} 00^{\prime \prime} \mathrm{E}$ and between latitudes $05^{\circ} 00^{\prime} 00^{\prime \prime}$ and $07^{\circ} 30^{\prime} 00^{\prime \prime} \mathrm{S}$ (see Figure 1). The basin includes two major rivers, the Wami and Ruvu, which cover areas of approximately 40,000 and $17,700 \mathrm{~km}^{2}$, respectively. The basin also includes coastal rivers located from the north to the southern part of Dar es Salaam. From an administrative viewpoint, the WRB comprises six cities, and hydrologically, the basin is divided into three river catchments: the Wami catchment, the Ruvu catchment, and the Coast catchment. The basin contains two estuaries, two national parks (Mikumi and Saadani), and two forest reserves. The Wami River basin (Kinyasungwe, Mkondoa, and Wami sub-catchments), Ruvu River basin (Upper Ruvu, Ngerengere, and Lower Ruvu sub-catchments), and Coastal catchment are jointly managed by the Wami Ruvu Basin Water Office (WRBWO) of the Tanzanian Ministry of Water and Irrigation.

\subsection{Input Data and Model Development}

As inputs to the model, climatic, hydrological, biophysical, and water demand data were obtained from different sources and archives. Demographic data were obtained from the Tanzanian National Bureau of Statistics (NBS), sectorial water consumption data (domestic, industrial, irrigation, and livestock) were obtained from the WRBWO, and hydro-climatic and meteorological data (e.g., stream flows, temperature, precipitation, and rainfall) from the years 1986-2015 were obtained from the Tanzania Meteorological Agency (TMA).The WEAP model was chosen because of its user-friendly, well-documented, has enough flexibility to adopt different levels of data availability with a friendly graphical user interface and advantage in dealing with distributed basin demand sites in large spatial scale. The WEAP model was 
used to simulate natural hydrological processes (e.g., evapotranspiration, runoff, and infiltration) and anthropogenic activities such as agriculture and their water allocations between upstream and downstream users. WEAP allows the balancing supply and demand, prediction and evaluation of "what if" scenarios, and water policies such as water demand management practices, hydrologic changes, new infrastructure, and changes in allocations or operations [15,18,19]

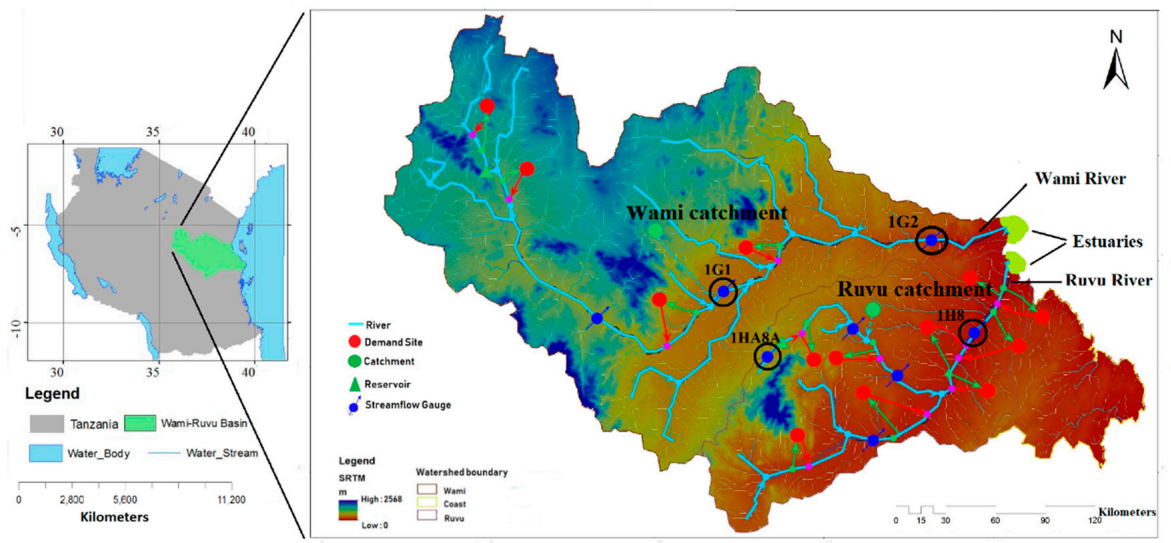

Figure 1. Map of the Wami Ruvu Basin located in Eastern Tanzania. Left: location of the basin; right: Water Evaluation and Planning system (WEAP) schematic diagram.

\subsubsection{Demand Sites and Supply Sources}

The demand sites and their corresponding annual activity levels were identified from previous studies, such as the Wami Ruvu Basin Water Atlas developed by Florida International University (FIU) [20], the Integrated Water, Sanitation and Hygiene (iWASH) Program [21], and the Global Water for Sustainability Program [22]. The demand is the product of the total activity level and sectorial water use rates [15]. The major demand sites in the basin are Dodoma, Morogoro, Pwani, Dar es Salaam, Tanga, and Manyara (see Table 1). All supply sources of the existing and planned developments in the WRB are fed from surface water resources of the main rivers (the Wami and Ruvu rivers), tributaries, and reservoirs that supply water for domestic purposes.

Table 1. Information of the population within the Wami Ruvu basin.

\begin{tabular}{cccc}
\hline City & Abbreviation & Population & Water Demand $\left(\mathbf{m}^{3} /\right.$ year $)$ \\
\hline Dodoma & Dom & $1,213,835$ & $20,381,321$ \\
Morogoro & Moro & $1,536,779$ & $32,149,814$ \\
Pwani & Pwan & 825,135 & $16,725,398$ \\
Dar es Salaam & Dar & $4,245,127$ & $256,119,646$ \\
Tanga & Tanga & 175,176 & $1,678,403$ \\
Manyara & Manyr & 125,408 & $1,201,566$ \\
\hline & & Source: $[1,2]$.
\end{tabular}

\subsubsection{Model Configuration}

The model was first configured for the whole basin in the form of a continuous set of two sub-catchments, namely the Wami and Ruvu sub-catchments. The water system was characterized by demand sites, reservoirs, flow gauging stations, and river head flows. The boundaries of the study area were used to describe the spatial location of the water system. The demand site, reservoir, and catchment sources were represented with nodes. These nodes were linked to the Wami and Ruvu rivers through transmission links and return flow links. The demand site nodes were created in the schematic view at relative positions (see Figure 1).

Additionally, demand priorities, representing the priority level for the allocation of the available water resource, were set. This means, for example, that all of the demand sites with the highest priority 
would be supplied first, before moving to lower priority sites until all of the demands are met or all the available resources are used, this represents the "current trend" scenario. However, in order to promote the economic growth scenario (hereafter referred to as "economic growth"), equitable water allocation in sectors and the prioritization of water use rights (hereafter known as "demand side management") is a prerequisite for examining the effects and implications of abrupt growth in water demand in the WRB. It should be noted that the current study provides a snapshot of the actual water demand, resources, and supplies to the system for the current or baseline year, which was chosen to be the year 2015.

Due to the high degree of interactions between ecosystems, demand, and supply in the related sectors, water flow records at gauging stations 1G1, 1G2, 1HA8A, and 1H8 were used in our study. The gaps in the data were filled by linear interpolation between the previous and following (non-missing) values. The simulated irrigation water requirement and sectorial water allocations for domestic, livestock, and industry were quantified to allow analysis.

After the configuration of the model and the computation of sectorial demand, the model performances were assessed using the Nash-Sutcliffe coefficient $(E)$ and Pearson's square method $\left(R^{2}\right)$. The model-interpolated inputs (assign input time-series for each WEAP catchment object for the climate data) and created parameters (GDP growth, industrial growth, urbanization rate, population growth, and irrigation efficiency) were determined for the entire simulation period. Monthly river flow data from 1986-2015 at gauging stations 1H8 (Ruvu catchment), 1G1 (Wami catchment), and 1HA8A (Ngerengere catchment) were used. The model was run using a monthly time step (12 time-steps per year), giving both $E>50 \%$ and $R^{2}>50 \%$, which indicates acceptable hydrological model performance [23].

The model was tested using different sectorial water-demand scenarios, including (1) the scenario when the existing trend persists (Current Trend (CT) scenario), when uncoordinated water management practices continue and neither resource allocation nor priority setting between downstream and upstream water users are in place, and (2) the scenario when growth reaches double digits by 2035 (Economic Growth (EG) scenario, especially regarding the industrial sector growth). The population growth, GDP growth, industrial growth, and urbanization rate were raised to $6 \%, 10 \%, 11 \%$, and $85 \%$ respectively, due to Tanzania's expected transformation to a middle-income country.

Additionally, the possible impacts of water demand management policies, such as allocation priorities, integrated water resource management, and efficient water use in domestic and irrigation sectors (Demand Side Management (DSM) scenario) were examined. The DSM strategy focuses on the irrigation and domestic sectors since irrigation is the highest water consumer followed by the domestic sector. An irrigation water efficiency of $15 \%-30 \%$ (drip irrigation, sprinklers, etc.) and a domestic water use conveyance efficiency of $35 \%$ (which is assumed to have increased from the current value of 10\%) were assumed.

For each scenario, the main outputs analyzed included the extent of satisfying the water demand of different sectors, the degree to which the instream flow requirements are satisfied, and the spatial and temporal variation in water shortages, if any.

\subsection{Model Performance}

Due to data limitations, the short flow records from 2005 to 2015, which include both drier and wetter years, recorded at gauging stations $1 \mathrm{G} 1$ and $1 \mathrm{H} 8$, were chosen to evaluate the model performance. This approach has also been used to evaluate model performances in the Didessa sub-basin [7] and the South Phuthiatsana catchment [24]. The model stream flows were manually calibrated by altering the model parameters (through trial and error) to have the best fit between the simulated and observed flow [23]. Coefficient of determination $\left(R^{2}\right)$ ranges from 0 to 1 , with higher values indicating less error variance, and typically values greater than 0.5 are considered acceptable, and the Nash-Sutcliffe Efficiency $(E)$ ranges between $-\infty$ and 1.0 ( 1 inclusive), with $E=1$ being the optimal value. Values between 0.0 and 1.0 are generally viewed as acceptable levels of performance, with higher values of $E$ and $R^{2}$ indicating better agreement. The Nash-Sutcliffe Efficiency, $E$ and 
Coefficient of determination, $R^{2}$ [23], were used to assess the model performances and are calculated using Equations (1) and (2):

$$
\begin{gathered}
E=1.0-\frac{\sum_{i=1}^{N}\left(Q_{o_{i}}-Q_{s_{i}}\right)^{2}}{\sum_{i=1}^{N}\left(Q_{o_{i}}-\widetilde{Q}\right)^{2}} \\
R^{2}=1.0-\frac{\sum_{i=1}^{N}\left(Q_{s_{i}}-\widetilde{Q}_{s_{i}}\right)^{2}}{\sum_{i=1}^{N}\left(Q_{o_{i}}-\widetilde{Q}_{o_{i}}\right)^{2}}
\end{gathered}
$$

where, $Q_{o_{i}}$ is the observed streamflow $\left(\mathrm{m}^{3} / \mathrm{s}\right), Q_{s_{i}}$ is the simulated streamflow $\left(\mathrm{m}^{3} / \mathrm{s}\right), \widetilde{Q}$ is the average streamflow $\left(\mathrm{m}^{3} / \mathrm{s}\right)$ and $N$ is the total number of observations.

The sensitivity of the model to discharge variation was tested using the Water Year Method (WYM), which is a built-in function in the WEAP model that represents variation in climatic data, such as stream flow and rainfall. The method involves defining how different climatic regimes (e.g., very dry, dry, very wet, wet) compare to a normal year, which is given a value of 1 . The method specifies how much more or less water flows into the system in a given year relative to a normal year $[15,16]$.

\section{Results}

The results of the model performance assessed using $E$ and $R^{2}$ indicate that the performances for the Wami River during calibration $\left(E=0.69, R^{2}=0.74\right)$ and validation $\left(E=0.63, R^{2}=0.77\right)$ and for the Ruvu River during calibration $\left(E=0.70, R^{2}=0.76\right)$ and validation $\left(E=0.51, R^{2}=0.60\right)$ were all satisfactory, as shown in Figure 2. After calibration and validation, the WEAP model was conditioned to the year 2035 by introducing the three different scenarios (CT, EG, and DSM) over the entire simulation period. From the simulated hydrographs, it can be seen that the land-use changes that may occur in the years 2010-2015 along the Wami River (gauging station 1G1) and Ruvu river (gauging station 1H8) led to an increase in the peak flow in 2015 and 2013, respectively. These land cover changes are mainly from forest to agricultural and urban areas, which escalates the competition for freshwater for agricultural, livestock, industrial, and domestic demands. The expansion of agricultural and urban areas leads to a high level of environment damage.

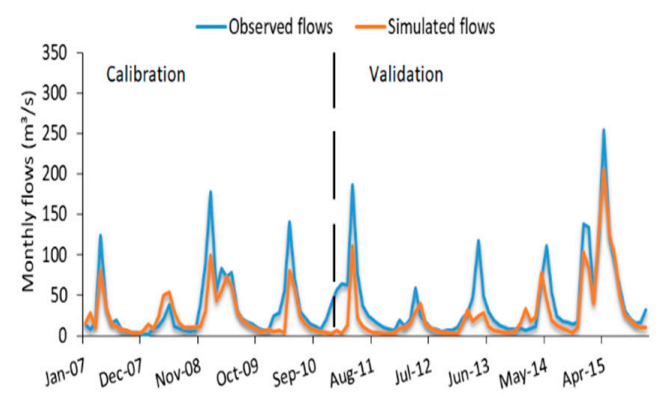

(a)

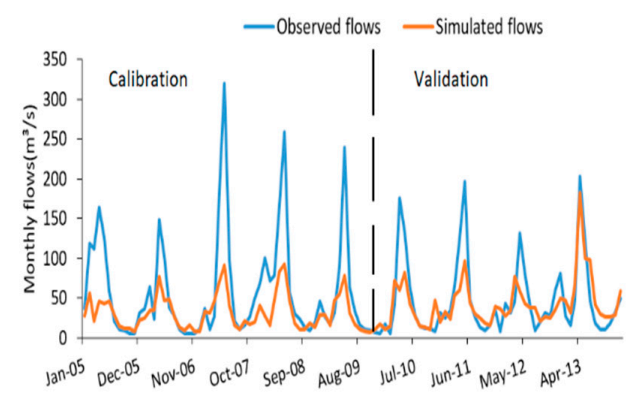

(b)

Figure 2. Model performance results for (a) the $1 \mathrm{G} 1$ gauging station, Wami River, and (b) the $1 \mathrm{H} 8$ gauging station, Ruvu River.

\subsection{Spatial and Temporal Trends in Water Supply and Demand}

The results show that downstream sub-catchments have a higher surface water potential in the Wami River basin. On the contrary, upstream sub-catchments have a higher surface water potential in the Ruvu River basin, especially in the Upper Ruvu sub-catchment, which has the highest surface water potential of the seven sub-catchments. The annual flow reduction impacts all seven sub-catchments in 
the basin (see Figure 3a and Table S1). Flow reduction trends have also impacted riparian areas in other basins in the region [6-8,25] (see Figure $3 b$ and Table S2).

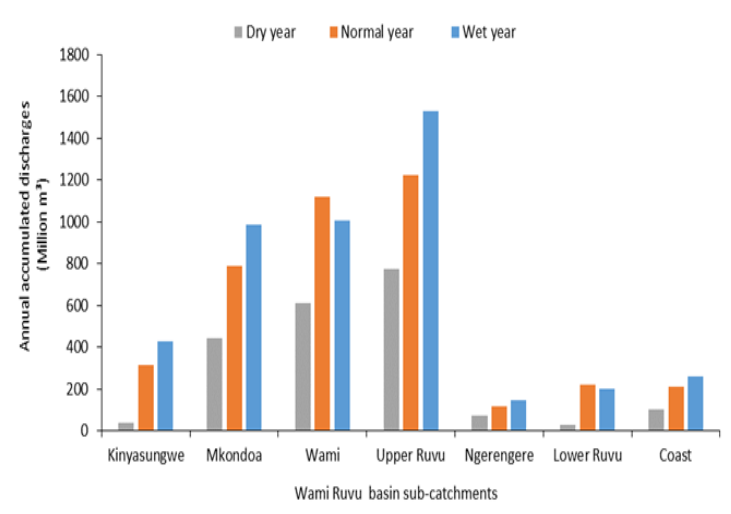

(a)

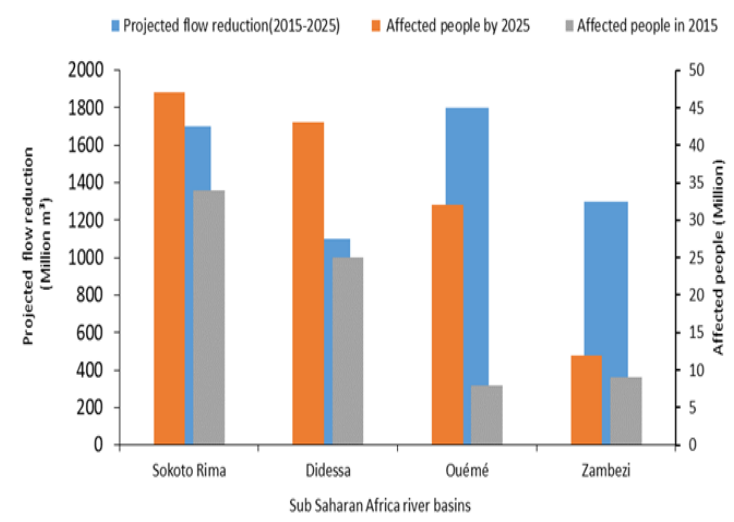

(b)

Figure 3. Variation in basin flow: (a) annual accumulated discharge in the Wami Ruvu basin; (b) annual flow reductions and affected riparian areas in Sub-Saharan Africa (selected basins).

Water demand projections at all nodes showed remarkable increases in the water abstraction level at all abstraction points. The analysis found that the major demand nodes for the water utilized were domestic and irrigation consumption (see Table 2). Under the CT scenario, the total water demand in the WRB is projected to rise from 1050.0 million $\mathrm{m}^{3}$ in the year 2015 to 2122.9 million $\mathrm{m}^{3}$ in the year 2035, and under the DSM scenario the total water demand is projected to rise from 990.0 million $\mathrm{m}^{3}$ in the year 2015 to 1715.8 million $\mathrm{m}^{3}$ in the year 2035. Comparatively, under the DSM scenario, the average annual water demands are projected to decrease by $15 \%$ in each target year, from 1586.5 million $\mathrm{m}^{3}$ in 2015 to 1352.9 million $\mathrm{m}^{3}$ in 2035 (see Figure 4a and Table S3). Land use changes influenced by terrestrial water demand alter the hydrological cycle of a catchment by modifying parameters such as surface runoff, particularly in small catchments (see Figure $4 \mathrm{~b}$ and Table S4).

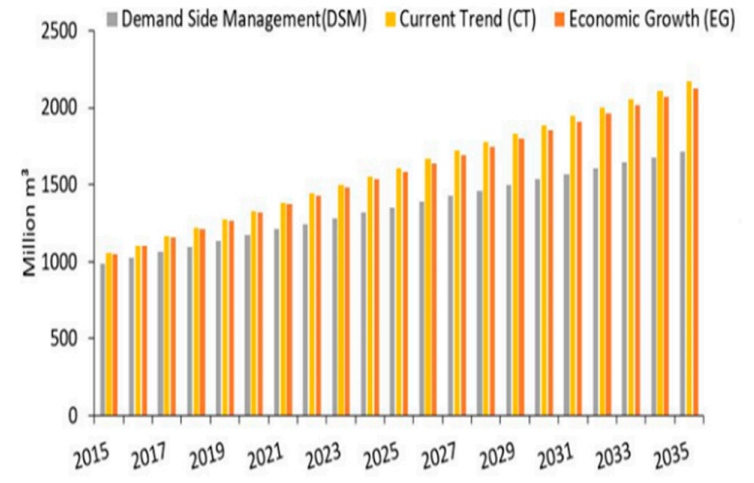

(a)

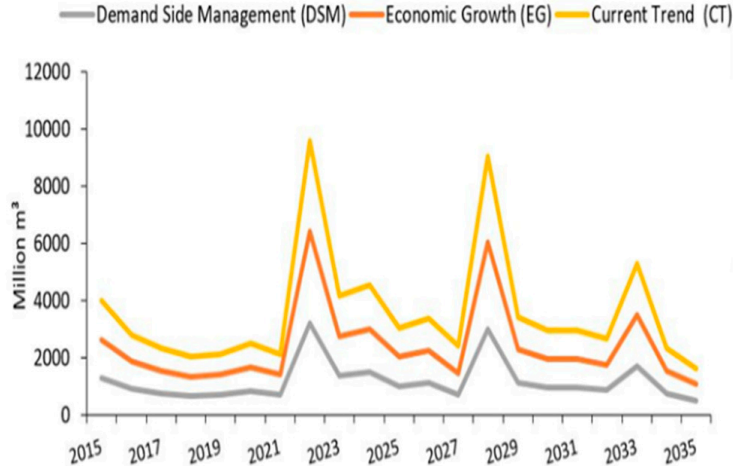

(b)

Figure 4. The impact of the various scenarios on (a) growth in water demand and (b) surface runoff trends.

Table 2. Sectorial water demand in the Wami Ruvu basin.

\begin{tabular}{ccc}
\hline Sectors & City & Water Demand $\left(\mathbf{m}^{\mathbf{3}} /\right.$ year) \\
\hline Irrigation & Dar, Pwan, Moro, Dom & $652,800,000$ \\
Domestic & Dar, Pwan, Moro, Dom & $325,300,000$ \\
Industry & Dar, Moro & $60,600,000$ \\
Livestock & Dar, Moro, Dom & $11,300,000$ \\
\hline
\end{tabular}




\subsection{Projection of Unmet Water Demands}

The highest unmet demand trends seen in the Mkondoa and Wami sub-catchments are mainly due to the expansion of irrigated agriculture, while the unmet demands in the Kinyasungwe sub-catchment are caused by semi-arid conditions and the growing population of the area (see Figure 5 and Table S5). The increase in the amount of unmet demand corresponds to the demand growth (see Figures 4a and 6a). Therefore, the current trend scenario, which has the highest demand (from irrigation and domestic sectors), also has the highest unmet demand, which in turn impacts the sectorial water demand coverage (see Figure 6b). Since 2010, the increase in supply has never met the growing demand. There are three major reasons for the increase in unmet demand in the domestic and agriculture sectors: (1) higher per capita water use rates and population growth, (2) the expansion of irrigated land, and (3) declining water inflow to the catchments due to discharge variability and an increase in anthropogenic activities (agriculture, industry, habitation, and deforestation).

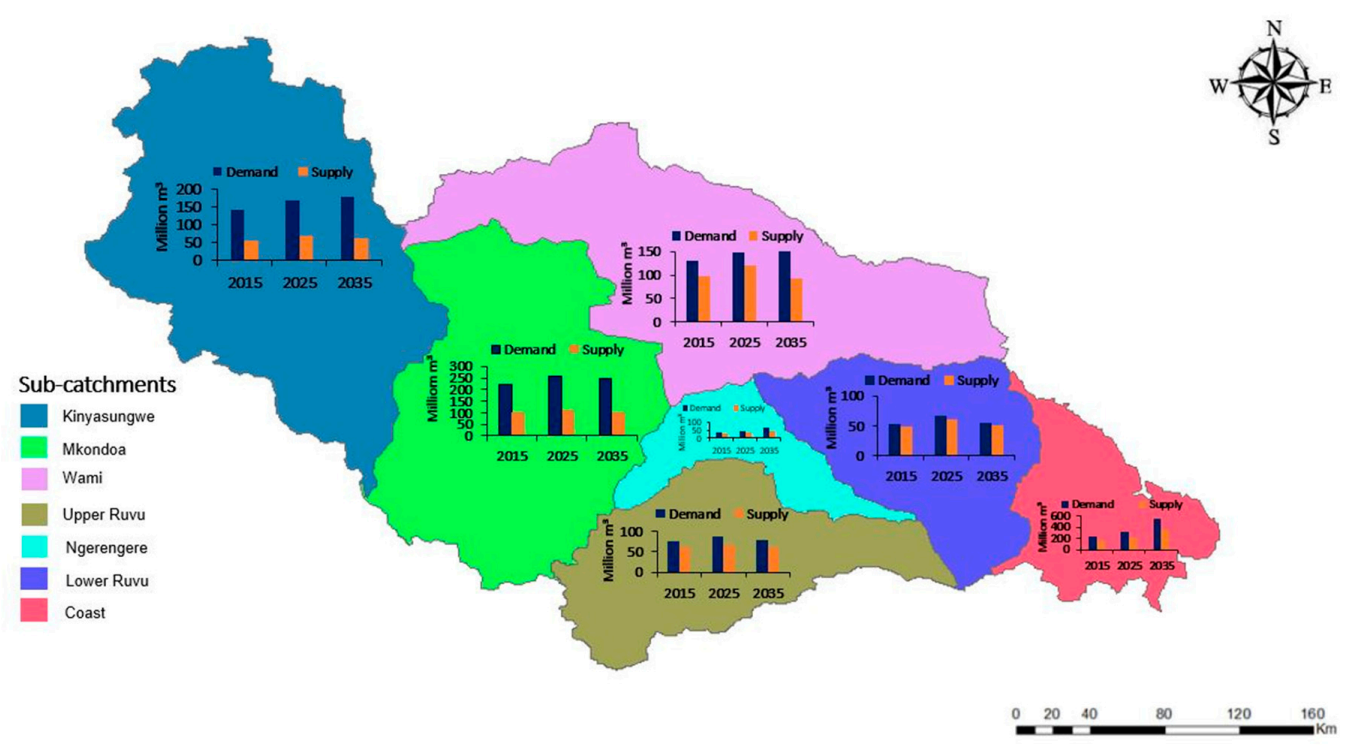

Figure 5. Projected spatial and temporal variation in water supply and demand in the Wami Ruvu basin.

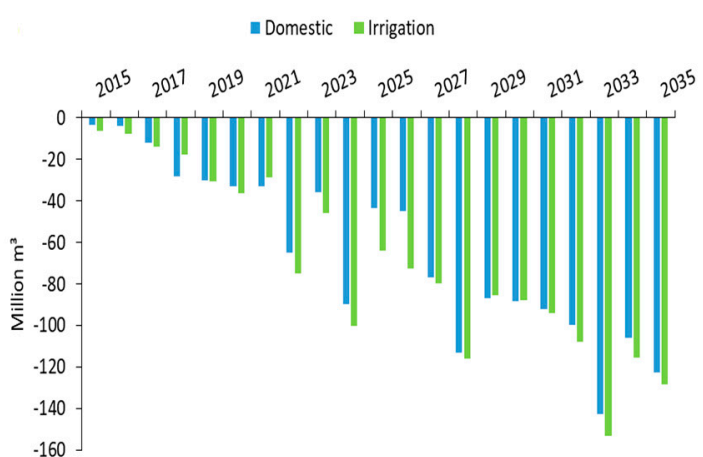

(a)

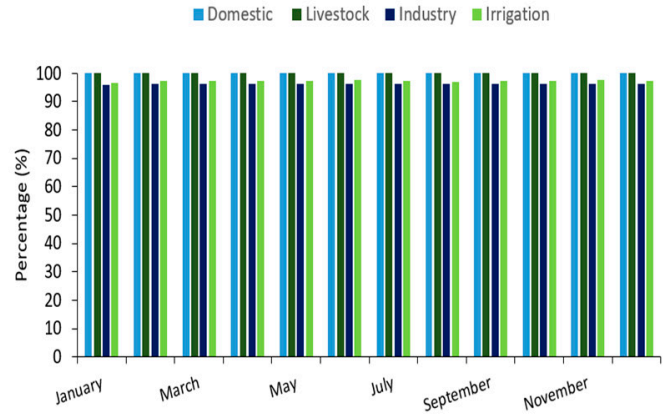

(b)

Figure 6. (a) Sectorial unmet demands under the Current Trend (CT) scenario, and (b) sectorial demand coverage under the Demand Side Management (DSM) strategies.

\subsection{Analysis of Scenarios}

\subsubsection{Impacts of Discharge Variability on Water Demand}

The WRB experiences a $14 \%$ increase in surface water discharge during wet years, and a $48 \%$ decline in surface water discharge in dry years, the latter of which has a severe impact on the Ngerengere, 
Lower Ruvu, Coast, and Kinyasungwe sub-catchments (see Figure 3a). The annual average river flows recorded between 1986 and 2015 at the stations nearest to the estuaries show that river flows to the Wami estuary decreased by $29 \%$, from 57.4 to $40.6 \mathrm{~m}^{3} / \mathrm{s}$, and river flows to the Ruvu estuary decreased by $27 \%$, from 58.7 to $43.1 \mathrm{~m}^{3} / \mathrm{s}$ (Figure 7). The annual reduction in river flow and increase in the number of riparian areas affected by water tension are strongly correlated in river basins in SSA, as shown by a sharp increase in the number of people affected by water tension towards 2025 (see Figure 3b). Thus, the reliability and resilience of the water system will tend to decrease, and the vulnerability of the water system will consequently increase.

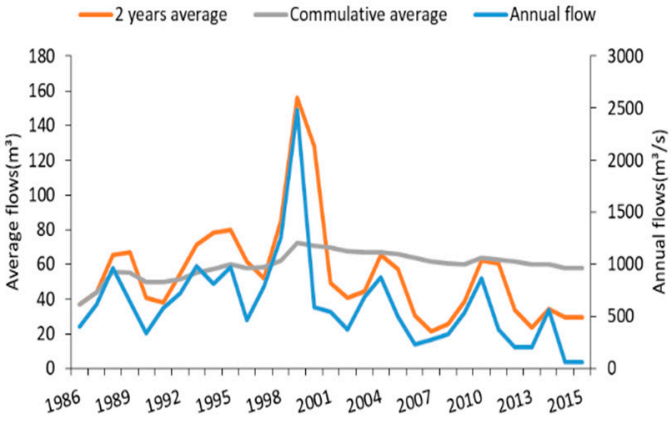

(a)

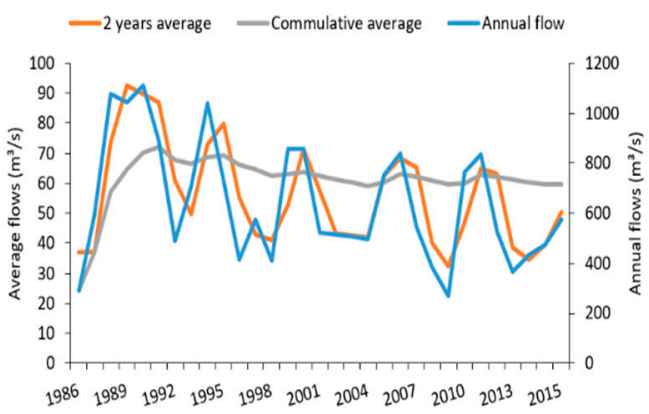

(b)

Figure 7. River flows along (a) the Wami estuary and (b) the Ruvu estuary.

\subsubsection{Impact of Water Demand on River Flows}

The average annual surface runoff is lower under the DSM scenario $\left(1184.9\right.$ million $\left.\mathrm{m}^{3}\right)$ than under the EG scenario (1200.6 million $\mathrm{m}^{3}$ ) and CT scenario (1209.2 million $\mathrm{m}^{3}$ ), implying that DSM strategies reduce runoff by 24.2 million $\mathrm{m}^{3}(2 \%)$ in each target year (see Figure $4 \mathrm{~b}$ ). The average demand site coverage under the DSM scenario is $96 \%$, whereby all water needs are met (100\% coverage for domestic and livestock sectors), albeit with slight fluctuations at the irrigation nodes, as they are water-intensive activities (see Figure 6b). The DSM scenario appears more promising than the CT and EG scenarios, as it cuts water demand by an average of $15 \%$ and lowers surface runoff by $2 \%$ annually. The results show that there is a positive correlation between the highest surface runoff events and the highest unmet demand events in the basin in the WRB, particularly for the years 2022, 2024, 2028, and 2033 (see Figures $4 \mathrm{~b}$ and $6 a$ ).

\section{Discussion}

\subsection{Mitigating Hydro-Climatic Impacts on Water Demand}

Rainfall and human population density are strongly correlated in African river basins. At the continental scale, demographic impacts will largely drive the substantial extension of water-stressed zones $[3,26]$. The impacts of hydro-climatic variability extend to economic growth in most countries in SSA. For example, the occurrence of droughts and floods reduced Ethiopia's GDP growth by more than one third, and Kenya suffered annual reductions in GDP of 10\%-16\% due to flooding associated with El Niño in 1997-1998 and drought associated with La Niña in 1998-2000 [27]. DSM strategies, such as setting water allocation priorities among users, efficient water utilization, and the development of the water supply through the storage of surface water in reservoirs as well as inter-basin transfers and the reuse of treated water, are useful to enhance water and economic security in water-stressed regions.

\subsection{Enhancing Future Water Sustainability}

The results of this study show that the river flows in the WRB have been declining, as have the river flows towards estuaries. Other studies have shown that between 1987 and 2010 the basin's agricultural area has increased by $3.17 \%$, the areas of forest and water bodies have decreased by 
$1.36 \%$ and $0.48 \%$ respectively [28], and forest cover has declined by $12 \%$ in the Ruvu catchment [29]. Additionally, competition for freshwater for agricultural, livestock, industrial, and domestic uses is reducing, which in some cases is eliminating freshwater flows to the environment.

Around 110 species of amphibian and 22 species of reptiles are threatened with extinction in the WRB, largely due to high rates of water abstraction, deforestation, and water pollution [20-22]. Balancing water supply and enforcing minimum environmental water flow requirements will play an increasingly large role in future sustainability plans and need to be considered as an integral part of water management in all river system development scenarios.

\subsection{Resilience and Reliability of Water Systems}

Water resources are inextricably linked with climate, and the prospect of global climate change has serious implications for future water resources and regional development [1,2,30-32]. The large variation in the spatial and temporal distribution of water resources in the Sokoto Rima River basin, the Didessa sub-basin, the Niger River basin, etc., will make the consequences of water scarcity even more severe unless DSM strategies are implemented which prove to be effective in minimizing the future growth in water demand and basin surface runoff.

Utility coverage rates are falling in urban Africa, the continent's population density is increasing, and there is a perception that groundwater is of better quality (clear, cool, and relatively unpolluted) than water in streams and rivers, with the rapid growth of boreholes showing the appetite for lower-cost water solutions in the continent. Groundwater from water wells (boreholes and hand-dug wells) now supplies one-fourth of Africa's urban population, and is by far the fastest-growing source of improved water supply in African cities [33] (e.g., in Djibouti, Mauritania, and South Africa). In this regard, integrated groundwater and surface water utilization is important to augment insufficient water supplies derived from surface water.

\section{Conclusions}

Overall, estimates of the future increase in water use in African river basins primarily concentrate on the agricultural and domestic sectors. The results of this study reveal that DSM strategies would significantly improve water sustainability and ecosystem security, and would consequently balance the supply and demand between upstream and downstream areas.

In cases of gross imbalance between water supply and demand, one of the two following scenarios must occur: either supply has to be augmented through technological investments (such as inter-basin transfer, irrigation schemes, and changes in agricultural methods), or population densities have to be reduced via migrations from water-stressed zones.

Water demands and resources are projected to experience strain, and the pressure on water resources, ecosystems, and land is projected to increase. Current water-use practices contribute significantly to high surface runoff, implying that the expansion of agricultural and urban areas leads to large amounts of environment damage. Agricultural technologies for water saving, including sprinklers and varieties of water efficiency equipment, have improved efficiency plans and water conservation methods, and the allocation of priorities between upstream and downstream users appears to be the only option to mitigate eco-environmental problems and future demand-driven water stress in river basins.

Developing effective and reliable strategies for coping with climate variability and change, growing water scarcity, and the disappearance of water bodies, should be a key concern in any future water resource management plan. The construction of storage facilities such as dams and reservoirs in the WRB area will help to control water flow, combat low water levels, and ensure adequate amounts of drinking water for fast-growing cities such as Dar es Salaam and Bagamoyo. Additionally, it is recommended to use groundwater monitoring networks, especially in catchments where groundwater use is high, and to obtain a better understanding of the local connections between rainfall and water recharge. 
Supplementary Materials: The following are available online at http:/www.mdpi.com/2073-4441/11/6/1280/s1: Table S1: Accumulated river discharges; Table S2: Reductions in the annual river flow and affected riparian areas in basins in Sub-Saharan Africa (selected countries); Table S3: Projection of growth in water demand; Table S4: Surface runoff trends; Table S5: Spatial and temporal variation in water supply and demand.

Author Contributions: Formal analysis, M.M.; Funding acquisition, J.L.; Methodology, M.M.; Resources, J.L.; Supervision, C.Z.; Writing-original draft, M.M.

Funding: This study was supported by the National Key Research and Development Program (No.2016YFE0102400) of the Ministry of Science and Technology of China.

Acknowledgments: The authors acknowledge the support provided by the WRBWO officials, Niqbar Ally and Pascal Qutaw. The authors thank the anonymous reviewers for their helpful comments.

Conflicts of Interest: The authors declare no conflict of interest.

\section{References}

1. Rayne, S.; Forest, K. The decline of global per capita renewable internal freshwater resources. viXra. Available online: http://vixra.org/pdf/1301.0073v1.pdf (accessed on 19 June 2019).

2. Rodell, M.; Famiglietti, J.S.; Wiese, D.N.; Reager, J.T.; Beaudoing, H.K. Emerging trends in global freshwater availability. Nature 2018, 557, 651-659. [CrossRef]

3. McClain, M.E. Balancing water resources development and environmental sustainability in Africa: A review of recent research findings and applications. AMBIO 2013, 42, 549-565. [CrossRef] [PubMed]

4. Wada, Y.; Bierkens, M.F.P. Sustainability of global water use: Past reconstruction and future projections. Environ. Res. Lett. 2014, 9. [CrossRef]

5. Howells, M.; Hermann, S.; Welsch, M.; Bazilian, M.; Segerström, R.; Alfstad, T.; Gielen, D.; Rogner, H.; Fischer, G.; van Velthuizen, H.; et al. Integrated analysis of climate change, land-use, energy and water strategies. Nat. Clim. Chang. 2013, 3, 621-626. [CrossRef]

6. Abdullahi, S.A.; Muhammad, M.M.; Adeogun, B.K.; Mohammed, I.U. Assessment of water availability in the Sokoto Rima River Basin. Sci. Acad. Publ. 2014, 4, 220-233.

7. Adgolign, T.B.; Rao, G.V.R.S.; Abbulu, Y. WEAP modeling of surface water resources allocation in Didessa Sub-Basin, West Ethiopia. Sustain. Water Resour. Manag. 2016, 2, 55-70. [CrossRef]

8. Höllermann, B.; Giertz, S.; Diekkrüger, B. Benin 2025-Balancing Future Water Availability and Demand Using the WEAP "Water Evaluation and Planning" System. Water Resour. Manag. 2010, 24, 3591-3613. [CrossRef]

9. Johannsen, I.; Hengst, J.; Goll, A.; Höllermann, B.; Diekkrüger, B. Future of Water Supply and Demand in the Middle Drâa Valley, Morocco, under Climate and Land Use Change. Water 2016, 8, 313. [CrossRef]

10. George, O.; Metobwa, M.; Mourad, K.A.; Ribbe, L. Water demand simulation using WEAP 21: A case study of the Mara River Basin, Kenya. Int. J. Nat. Resour. Ecol. Manag. 2018, 3, 9-18.

11. Ngoran, S.D.; Xue, X.Z.; Wesseh, P.K. Signatures of water resources consumption on sustainable economic growth in Sub-Saharan African countries. Int. J. Sustain. Built Environ. 2016, 5, 114-122. [CrossRef]

12. Lévite, H.; Sally, H.; Cour, J. Testing water demand management scenarios in a water-stressed basin in South Africa: Application of the WEAP model. Phys. Chem. Earth 2003, 28, 779-786. [CrossRef]

13. Mutiga, J.K.; Mavengano, S.T.; Zhongbo, S.; Woldai, T.; Becht, R. Water Allocation as a Planning Tool to Minimise Water Use Conflicts in the Upper Ewaso Ng'iro North Basin, Kenya. Water Resour. Manag. 2010, 24, 3939-3959. [CrossRef]

14. Mounir, Z.M.; Ma, C.M.; Amadou, I. Application of water evaluation and planning (WEAP): A model to assess future water demands in the Niger River (in Niger Republic). Modern Appl. Sci. 2011, 5, 38-49. [CrossRef]

15. Purkey, D.; Galbraith, H.; Huber-Lee, A.; Sieber, J.; Yates, D. WEAP21-A Demand-, Priority-, and Preference-Driven Water Planning Model. Water Int. 2009, 30, 501-512.

16. Stockholm Environment Institute. WEAP-TUTORIAL Water Evaluation and Planning System. In WEAP; Stockholm Environment Institute: Boston, MA, USA, 2016.

17. Melesse, A.M.; Abtew, W.; Setegn, S.G. Nile River Basin: Ecohydrological Challenges, Climate Change and Hydropolitics; Springer: Berlin/Heidelberg, Germany, 2013; pp. 1-718.

18. Raskina, P.; Hansen, E.; Zhu, Z.; Stavisky, D. Simulation of water supply and demand in the aral sea region. Water Int. 1992, 17, 55-67. [CrossRef] 
19. Yates, D.; Sieber, J.; Purkey, D.; Huber-Lee, A. WEAP21-A Demand-, Priority-, and Preference-Driven Water Planning Model Part 1: Model Characteristics. Water Int. 2005, 30, 487-500. [CrossRef]

20. Saha, A.; Donoso, M.; Mohamed, A.; Masikini, R.; Abbott, V.; Anderson, E. Water Atlas of the Wami/Ruvu Basin, Tanzania; Florida International University: Miami, FL, USA, 2014.

21. GLOWS-FIU. Socioeconomic Conditions and Links to Freshwater Ecosystem Services of the Ruvu River Basin, Tanzania; Global Water for Sustainability Program, Florida International University: Miami, FL, USA, 2013; Volume 38.

22. GLOWSFIU. Climate, Forest Cover, and Water Resources Vulnerability Wami/Ruvu Basin, Tanzania; GLOWSFIU: Miami, FL, USA, 2014; ISBN 9781941993033.

23. Moriasi, D.N.; Arnold, J.G.; Van Liew, M.W.; Bingner, R.L.; Harmel, R.D.; Veith, T.L. Model evaluation guidelines for systematic quantification of accuracy in watershed simulations. Trans. ASABE 2007, 50, 885-900. [CrossRef]

24. Maliehe, M.; Mulungu, D.M.M. short 2. Phys. Chem. Earth 2017, 100, 305-316. [CrossRef]

25. Spalding-fecher, D.R. Impact of Climate Change and Irrigation Development on Hydropower Supply in the Zambezi River Basin, and Implications for Power Sector Development in the Southern African Power Pool. Ph.D. Thesis, University of Cape Town, Cape Town, South Africa, 2018.

26. le Blanc, D.; Perez, R. The relationship between rainfall and human density and its implications for future water stress in Sub-Saharan Africa. Ecol. Econ. 2008, 66, 319-336. [CrossRef]

27. Brown, C.; Meeks, R.; Hunu, K.; Yu, W. Hydroclimate risk to economic growth in sub-Saharan Africa. Clim. Chang. 2011, 106, 621-647. [CrossRef]

28. Nobert, J. Hydrological response of watershed systems to land use/cover change. A case of Wami River Basin. Open Hydrol. J. 2012, 6, 78-87. [CrossRef]

29. Guzha, A.C.; Rufino, M.C.; Okoth, S.; Jacobs, S.; Nóbrega, R.L.B. Impacts of land use and land cover change on surface runoff, discharge and low flows: Evidence from East Africa. J. Hydrol. Reg. Stud. 2018, 15, 49-67. [CrossRef]

30. Chiarelli, D.D.; Davis, K.F.; Rulli, M.C.; D'Odorico, P. Climate change and large-scale land acquisitions in Africa: Quantifying the future impact on acquired water resources. Adv. Water Resour. 2016, 94, 231-237. [CrossRef]

31. Shiferaw, B.; Tesfaye, K.; Kassie, M.; Abate, T.; Prasanna, B.M.; Menkir, A. Managing vulnerability to drought and enhancing livelihood resilience in sub-Saharan Africa: Technological, institutional and policy options. Weather Clim. Extrem. 2014, 3, 67-79. [CrossRef]

32. Mutiga, J.K.; Zhongbo, S.; Woldai, T. Impacts of agricultural intensification through upscaling of suitable rainwater harvesting technologies in the upper Ewaso Ng'iro North basin, Kenya. Hydrol. Earth Syst. Sci. Discuss. 2011, 8, 2477-2501. [CrossRef]

33. Bank, W. Assessment of Groundwater Challenges and Opportunities in Support of Sustainable Development in Sub-Saharan Africa; World Bank: Washington, DC, USA, 2018.

(C) 2019 by the authors. Licensee MDPI, Basel, Switzerland. This article is an open access article distributed under the terms and conditions of the Creative Commons Attribution (CC BY) license (http://creativecommons.org/licenses/by/4.0/). 